\title{
Impacts of the IUCN Red List of Ecosystems on Conservation Policy and
}

\section{Practice}

Running title: Impacts of the IUCN Red List of Ecosystems

Lucie M. Bland ${ }^{1}$, Emily Nicholson ${ }^{1}$, Rebecca M. Miller ${ }^{2}$, Angela Andrade ${ }^{2,3}$, Andres Etter $^{4}$, José Rafael Ferrer-Paris ${ }^{5,6}$, Tytti Kontula ${ }^{7}$, Arild Lindgaard ${ }^{8}$, Patricio Pliscoff ${ }^{9}$, Andrew Skowno $^{10}$, Irene Zager ${ }^{6}$, David A. Keith ${ }^{11,12,13}$

${ }^{1}$ School of Life and Environmental Sciences, Centre for Integrative Ecology, Deakin University, Burwood, Victoria 3125, Australia

${ }^{2}$ IUCN Commission on Ecosystem Management

${ }^{3}$ Conservation International, Colombia

${ }^{4}$ Facultad de Estudios Ambientales y Rurales. Pontificia Universidad Javeriana. Bogotá, Colombia

${ }^{5}$ Centro de Estudios Botánicos y Agroforestales, Instituto Venezolano de Investigaciones Científicas, Av 8

Calle 79/80 Edif MICA, Maracaibo 4005, Venezuela

${ }^{6}$ Provita, Apdo. 47552, Caracas 1041-A, Venezuela

${ }^{7}$ Finnish Environment Institute, FIN-00790 Helsinki, Finland

${ }^{8}$ Norwegian Biodiversity Information Centre (Artsdatabanken), PB1058, 7446 Trondheim, Norway

${ }^{9}$ Instituto de Geografía y Departamento de Ecología, Pontificia Universidad Católica de Chile, Av. Libertador Bernardo O’Higgins 340, Santiago 8331150, Chile

${ }^{10}$ South African National Biodiversity Institute, Kirstenbosch Research Centre, Cape Town, South Africa

${ }^{11}$ Centre for Ecosystem Science, School of Biological, Earth and Environmental Science, University of New South Wales, Kensington, 2052, New South Wales, Australia

${ }^{12}$ New South Wales Office of Environment and Heritage, Hurstville, 2220, New South Wales, Australia

${ }^{13}$ Long Term Ecological Research Network, Terrestrial Ecosystem Research Network, Australian National University, Canberra, 0200, Australian Capital Territory, Australia

Keywords: conservation practice, ecosystem, impact, IUCN Red List of Ecosystems, monitoring, risk assessment.

Corresponding author: Lucie M. Bland (1.bland@deakin.edu.au) 


\begin{abstract}
In 2014, the International Union for Conservation of Nature adopted the Red List of Ecosystems (IUCN RLE) criteria as the global standard for assessing risks to terrestrial, marine, and freshwater ecosystems. Identifying and quantifying the impacts of biodiversity assessments on the status of nature is key to justifying continued investment in assessments and enabling strategic planning to maximize future impact. In this policy perspective, we use an established impact evaluation framework to identify the impacts of the IUCN RLE since its inception. To date, 1,397 ecosystem units in 100 countries have been assessed following the IUCN RLE protocol. Systematic assessments are complete or underway in more than 25 countries and two continental regions (the Americas and Europe). Countries with established ecosystem red lists have already used them to inform legislation, land-use planning, protected area expansion, monitoring and reporting, and ecosystem management. IUCN RLE indices based on systematic assessments have high potential to inform global biodiversity reporting for the Aichi Targets and the United Nations Sustainable Development Goals. Expanding the coverage of IUCN RLE assessments, building capacity to undertake them, and establishing stronger policy instruments to manage red-listed ecosystems will be key to maximizing conservation impacts over the coming decades.
\end{abstract}




\section{Introduction}

Biodiversity conservation efforts are increasingly focusing on ecosystems to supplement and complement threatened species conservation (Rodríguez et al. 2011). Policy demand has led to the emergence of a number of ecosystem risk-assessment protocols among jurisdictions (Nicholson et al. 2009). In 2014, the International Union for Conservation of Nature (IUCN) adopted the Red List of Ecosystems (RLE) criteria as the global standard for assessing risks to ecosystems. The RLE uses five quantitative risk criteria to assess the risk of ecosystem collapse and is designed to be globally applicable to terrestrial, marine, and freshwater ecosystems (Keith et al. 2015; Bland et al. 2017).

Global biodiversity assessments (e.g., the IUCN RLE and the IUCN Red List of Threatened Species $^{\mathrm{TM}}$ ) influence conservation practice and policy at multiple levels. The development of a global assessment method for ecosystems provides a credible international standard for local conservation policy and management activities (Keith et al. 2015). It is also fundamental to tracking progress toward international policy targets, including the Aichi Targets of the Convention on Biological Diversity and the United Nations Sustainable Development Goals. Despite the importance of quantifying the impact of global biodiversity assessments to justify continued investments (Juffe-Bignoli et al. 2016), impacts are often difficult to identify and measure due to high levels of project complexity, diverse actor involvement, and varying stages of implementation.

Existing impact evaluation frameworks have the potential for adaptation to conservation and biodiversity assessments. The Commonwealth Scientific and Industrial Research Organisation (CSIRO) impact framework is used to consistently plan, monitor, and evaluate the impacts of CSIRO's research (CSIRO 2018). The CSIRO framework assesses how research translates into benefits in the real world by distinguishing research inputs, activities, 
outputs, and medium-term outcomes from long-term impacts (Figure 1). The CSIRO framework defines impact as an effect on, change or benefit to the economy, society and/or the environment beyond contributions to academic knowledge (CSIRO 2018). Reporting on biodiversity assessments has typically focused on outcomes (e.g., national and global adoption and number of units assessed; Juffe-Bignoli et al. 2016) rather than impacts (e.g., number of species saved from extinction and increases in human health and well-being). Social, environmental, and economic impacts tend to occur over longer timeframes, involve multiple actors, and may be indirectly related to research outputs (Morgan 2014).

In this policy perspective, we use an established impact evaluation framework (CSIRO 2018) to identify the impacts of the IUCN RLE since its inception (Rodríguez et al. 2011). Compared to other biodiversity data sources (such as the IUCN Red List of Threatened Species $^{\mathrm{TM}}$, the World Database on Protected Areas, and the World Database of Key Biodiversity Areas), the IUCN RLE is at a relatively early stage of implementation. As IUCN is celebrating its $70^{\text {th }}$ anniversary in 2018 , it is particularly timely to quantify the current impacts of the IUCN RLE and identify key challenges that must be addressed to maximize impact over the coming decades. We report on both outcomes and impacts to highlight the direct and indirect influences of the IUCN RLE (Figure 1). We also outline established pathways to impact based on the experience of countries with pre-existing ecosystem risk assessment protocols (hereafter referred to as ecosystem red lists). 


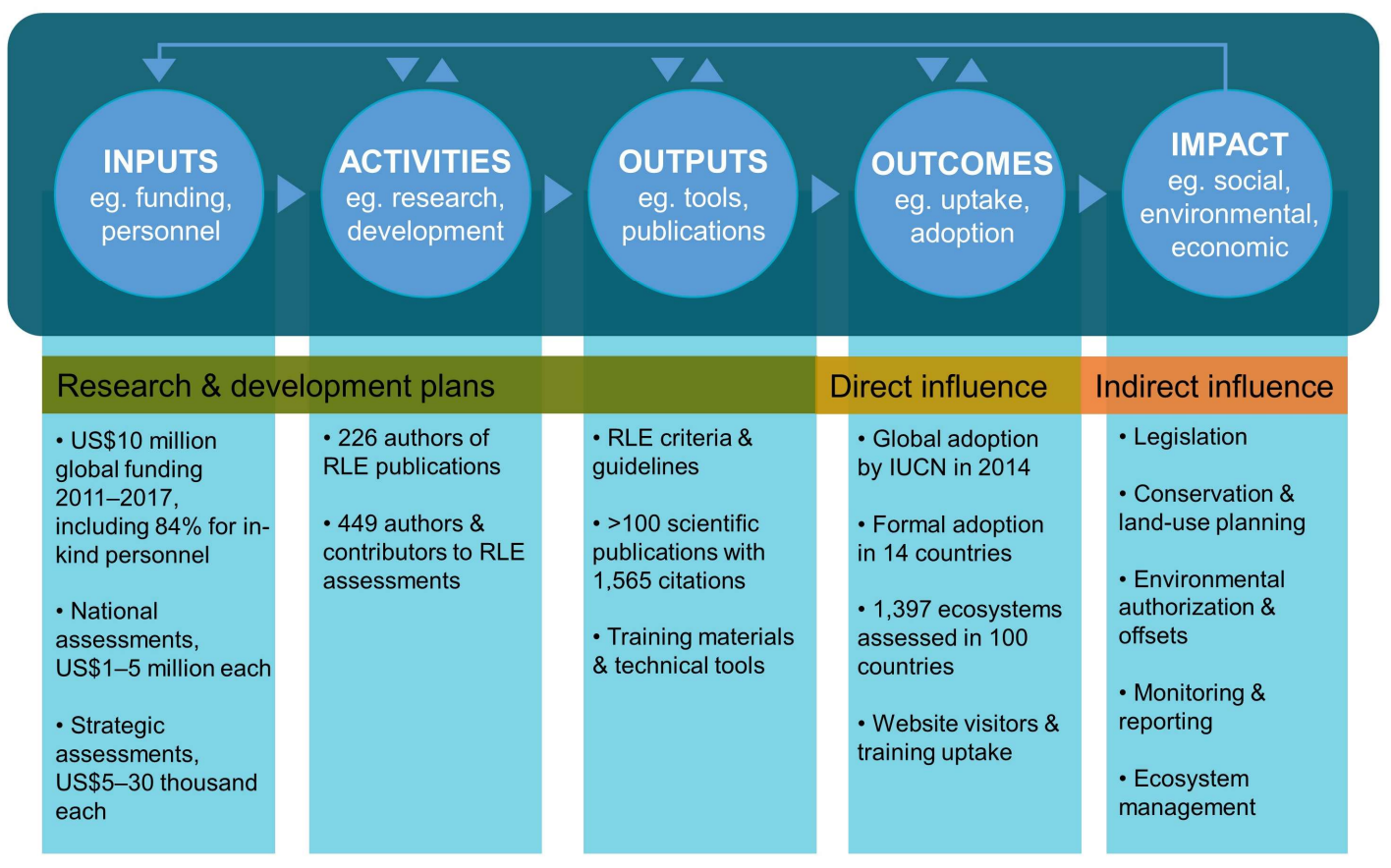

Figure 1. Impact evaluation of the International Union for Conservation of Nature Red List of Ecosystems (IUCN RLE), adapted from the Commonwealth Scientific and Industrial Research Organisation impact framework (CSIRO 2018).

\section{The IUCN RLE: from inputs to outcomes}

Research programs typically operate by deploying inputs (e.g., resources and staff) to complete activities (e.g., research and engagement) that lead to pre-defined outcomes (e.g., publications and methodologies; Figure 1). The IUCN RLE has attracted more than US\$10 million dollars of investment from 2011 to 2017 (E. Barrow, pers. comm.), including 84\% for personnel costs, most often in-kind (Juffe-Bignoli et al. 2016). National assessments have attracted from US\$740,000 to US\$3 million in funding (E. Barrow, pers. comm.). It has been estimated that an additional US\$43 million would be required to assess all the world's ecosystems by 2025 (Juffe-Bignoli et al. 2016). 
The first set of assessment guidelines, corresponding to version 2.2 of the RLE criteria, was issued in 2017 (Bland et al. 2017). There are more than 100 scientific publications related to the IUCN RLE (IUCN 2018). For a subset of those with digital object identifiers (DOI; $n=$ 63), we found 1,565 citations (Google Scholar), more than 3,000 readers in academic networks, and 1,646 posts in a range of web formats (e.g., social media, news feeds, research highlights, and policy papers; Altmetric). IUCN RLE publications have been co-authored by 226 individuals, while 449 authors and assessors contributed to IUCN RLE assessments. Training materials, tools (e.g., remote-sensing classification tools), and an online forum have supported the growing community of RLE practitioners (IUCN 2018). New technical infrastructure, including a website (http://iucnrle.org/) visited 76,300 times by users in 193 countries in its first 18 months, has enabled wide uptake of the RLE across the globe.

To date, 1,397 ecosystem units in 100 countries have been assessed (Table 1, Figure 2, and Table S1). The RLE criteria have been applied systematically to sets of ecosystem types within a geographical area (i.e., continental, national, and sub-national areas) and to single ecosystem types. Systematic assessments are complete or underway in more than 25 countries and two continental regions (the Americas and Europe), which together represent $\sim 47 \%$ of the earth's land surface (Figure 2). In Australia, the RLE criteria have been adopted as the Common Assessment Method to unite historically disparate listing methods across multiple jurisdictions (Nicholson et al. 2009). Several countries with established ecosystem red lists have already adopted the IUCN RLE criteria (i.e., Norway) or are in the process of doing so (Finland and South Africa). Countries with no prior red lists of ecosystems are also adopting the IUCN RLE (e.g., Chile; Pliscoff 2015). 
Table 1. Summary of the International Union for Conservation of Nature Red List of Ecosystems (IUCN RLE) continental, national, and sub-national assessments (IUCN RLE criteria versions 1 and 2). National assessments encompass all ecosystem types within a realm for a given country. Sub-national assessments encompass limited ecosystem types or geographical locations within a country. Strategic assessments of single ecosystems are shown in Table S1. T: terrestrial, M: marine, F: freshwater. NA: Not Available.

\begin{tabular}{|c|c|c|c|}
\hline & Realm & Ecosystem types & $\begin{array}{l}\text { Number of } \\
\text { ecosystem units }\end{array}$ \\
\hline \multicolumn{4}{|c|}{ Continental assessments } \\
\hline Americas & $\mathrm{T}$ & Forests & 136 \\
\hline Europe & $\mathrm{T}, \mathrm{M}, \mathrm{F}$ & & 490 \\
\hline \multicolumn{4}{|l|}{ National assessments } \\
\hline \multicolumn{4}{|l|}{ Completed } \\
\hline Chile & $\mathrm{T}$ & & 127 \\
\hline Colombia & $\mathrm{T}$ & & 81 \\
\hline Costa Rica & $\mathrm{T}$ & & 41 \\
\hline El Salvador & $\mathrm{T}$ & & 19 \\
\hline Norway & $\mathrm{T}, \mathrm{M}, \mathrm{F}$ & & 80 \\
\hline Paraguay & $\mathrm{T}$ & & 30 \\
\hline Senegal & $\mathrm{T}$ & & NA \\
\hline Switzerland & $\mathrm{T}, \mathrm{F}$ & & 167 \\
\hline \multicolumn{4}{|l|}{ Underway } \\
\hline China & $\mathrm{T}, \mathrm{M}, \mathrm{F}$ & & NA \\
\hline Czech Republic & $\mathrm{T}$ & & NA \\
\hline Finland & $\mathrm{T}, \mathrm{M}, \mathrm{F}$ & & 388 \\
\hline Madagascar & $\mathrm{T}, \mathrm{M}$ & & NA \\
\hline Myanmar & $\mathrm{T}$ & & NA \\
\hline Norway & $\mathrm{T}, \mathrm{M}, \mathrm{F}$ & & NA \\
\hline South Africa & $\mathrm{T}$ & & 459 \\
\hline \multicolumn{4}{|c|}{ Sub-national assessments } \\
\hline \multicolumn{4}{|l|}{ Completed } \\
\hline Brazil & $\mathrm{T}, \mathrm{F}$ & $\begin{array}{l}\text { Selected terrestrial and aquatic } \\
\text { ecosystems }\end{array}$ & 16 \\
\hline China & $\mathrm{T}$ & Southwest China & 105 \\
\hline Chile & $\mathrm{T}$ & $\begin{array}{l}\text { Sclerophyll forest and scrub } \\
\text { ecosystems }\end{array}$ & 20 \\
\hline Morocco & $\mathrm{T}$ & Forests & 14 \\
\hline New Zealand & $\mathrm{T}, \mathrm{F}$ & Rare ecosystems & 72 \\
\hline Venezuela & $\mathrm{T}$ & Selected vegetation units & 27 \\
\hline \multicolumn{4}{|l|}{ Underway } \\
\hline $\begin{array}{l}\text { Democratic Republic } \\
\text { of the Congo }\end{array}$ & $\mathrm{T}$ & NA & 66 \\
\hline Paraguay & $\mathrm{T}$ & NA & 30 \\
\hline
\end{tabular}




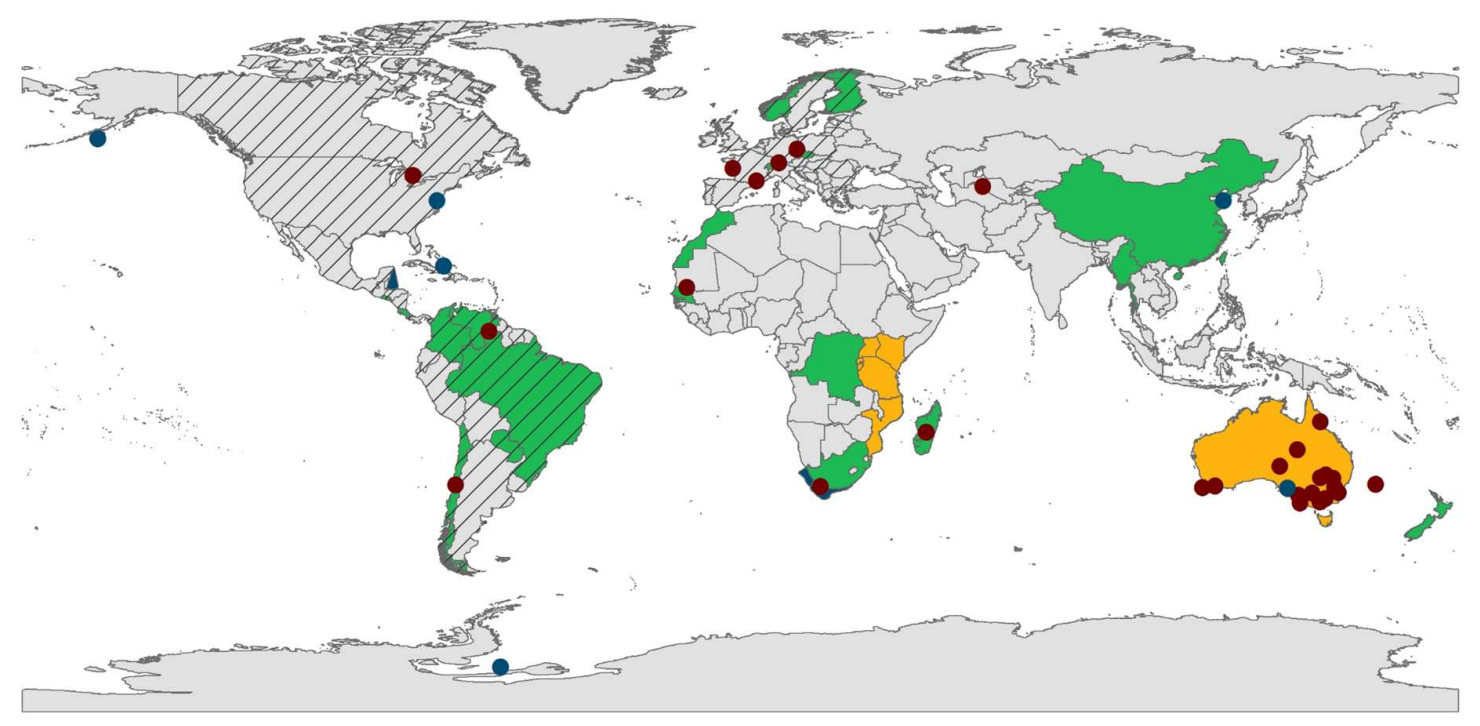

Figure 2. International Union for Conservation of Nature Red List of Ecosystems assessments conducted to date. Hatched areas: continental assessments. Green areas: national and sub-national assessments completed or underway. Orange areas: planned national assessments. Red circles: terrestrial strategic assessments. Blue circles and areas: marine strategic assessments.

Sub-national assessments of multiple ecosystem types have been conducted to provide targeted information on rare ecosystems (e.g., New Zealand; Holdaway et al. 2012) or on ecosystems that harbor concentrations of biodiversity (e.g., central Chile hotspot; Alaniz et al. 2016). Thirty-six strategic assessments of single ecosystems have been conducted (Table S1), which aim to diagnose key threats and evaluate alternative management scenarios to reduce risks (e.g., for the Australian mountain ash forest; Burns et al. 2015).

\section{Impacts of ecosystem red lists at the national scale}

Several countries are already using ecosystem red lists to inform conservation legislation, policy, and planning. This wide range of conservation impacts is particularly evident in countries with established ecosystem red lists (e.g., Norway, Finland, and South Africa), 
although early impacts are occurring in countries that are creating their first red lists with the IUCN RLE (e.g., Colombia).

\section{Legislation}

Threatened ecosystem assessments can act as regulatory triggers, where listed threatened ecosystems are legally protected by becoming automatic triggers for land use change applications. In Finland, the first systematic ecosystem assessment (Kontula \& Raunio 2009) lead to the incorporation of some threatened forests and mires into their Environment Protection Act and Forest Act. South Africa's third national assessment will continue the practice of regulatory protection and reporting for threatened ecosystems under the National Environmental Management: Biodiversity Act (Act 10 of 2004) (Republic of South Africa 2011). The Biodiversity Act requires that threatened ecosystems are taken into account by municipalities in their land-use and development planning. In Australia, the IUCN assessment of the Coastal Upland Swamps as Endangered (Keith et al. 2013) influenced statutory listing, legal protection, and government recommendations for changes to the design of proposed mines to minimize hydrological impacts. Three Australian states and territories have already incorporated the IUCN RLE into environmental laws and regulations.

\section{Conservation planning and protected area expansion}

Systematic and national assessments across realms (terrestrial, marine, and freshwater) enable ecosystem types to be compared, ranked, and prioritized within a conservation planning framework. In South Africa, threatened ecosystems are incorporated through systematic conservation planning into Bioregional Plans, which require that Critically Endangered and Endangered ecosystems are identified as 'critical biodiversity areas' (Republic of South Africa 2009). In areas where Bioregional Plans are gazetted, they constitute legal instruments that must be considered during land-use planning. Provisions are similar under the 
Environmental Protection and Biodiversity Conservation Act in Australia. Critically

Endangered and Endangered ecosystems are recognized as 'matters of national environmental significance' and are considered in developing Regional Plans.

Systematic conservation planning is also used as a basis for protected area expansion plans in South Africa, where ecosystem red lists inform priorities for protected area expansion to increase representation of threatened ecosystems. Similarly, Colombia has committed to increasing the extent of its protected area network from $12 \%$ to $17 \%$ of the country's land area by 2020 and the new IUCN RLE will inform the designation of new protected areas by identifying under-protected threatened ecosystems. The Chilean IUCN RLE was used to assess the severity of impacts caused by extensive fires in 2017 and to inform priorities for forest restoration, particularly on private land (Martinez-Harms et al. 2017).

\section{Environmental authorization and offsets}

In South Africa and Australia, regulations for environmental impact assessment state that Critically Endangered and Endangered ecosystems are direct triggers for full environmental impact assessments. National offset policy also uses threatened ecosystems to assess which impacts cannot be offset and sets higher minimum offset ratios for threatened ecosystems. In Colombia, the IUCN RLE has been included in Tremarctos

(http://www.tremarctoscolombia.org/), a tool that allows development projects (e.g., for road infrastructure and the energy and mining sectors) to take into account threatened ecosystems in the analysis of environmental, socioeconomic, and geophysical risks. The tool also allows for the calculation of offsets and compensations for non-mitigable impacts.

\section{Monitoring and reporting}

In South Africa, information on threatened ecosystems is used as a headline indicator in a number of national reporting frameworks, including the National Biodiversity Assessment 
and the South African Environmental Outlook. The requirements of the Convention on Biological Diversity are met through the compilation of national reports and a National Biodiversity Strategy and Action Plan (NBSAP), which report on the state of threatened ecosystems and policies to protect these ecosystems. IUCN RLE assessments in Norway have also been used as inputs for the country's NBSAP (Norwegian Ministry of Climate and Environment 2015) and they have been adopted as a basic input for a national mapping program on important ecosystem types. In Finland, the IUCN RLE serves as important background information for the European Union (EU) Habitats Directive Reporting and is currently being used to assess progress toward the EU Biodiversity Targets for 2020. In Colombia, the IUCN RLE has been included in National Biodiversity reports (Moreno et al. 2018).

\section{Voluntary ecosystem management}

Ecosystem red lists are used in a variety of innovative ways to inform voluntary ecosystem management. For example, the IUCN assessment of the mountain ash forest in Australia as Critically Endangered (Burns et al. 2015) triggered the establishment of an industry taskforce to provide recommendations for timber production, job security, and biodiversity objectives (www.forestindustrytaskforce.com.au). In South Africa, threatened ecosystems are mentioned in several eco-certification schemes, for example for the foresty and wine industries. The RLE serves as important input information together with the Red List for species within the Norwegian timber certification scheme (PEFC Norway 2015). In Finland, the Forest Biodiversity Programme for Southern Finland (METSO) aims to safeguard ecologically valuable forests (including threatened forests) by voluntary conservation.

\section{Social impacts}


The IUCN RLE has resulted in increased social cohesion in many countries where the criteria have been applied. The listing of Coastal Heaths as Endangered in Norway has resulted in high levels of community engagement to safeguard Coastal Heaths, which have depended on traditional land-use practices since the Bronze Age. Coastal Heaths have benefited from a National Action plan and been given status as a priority ecosystem type according to the Norwegian Nature Diversity Act. The IUCN RLE can therefore play an important role in sustaining landscapes of cultural importance.

A related benefit of systematic RLE assessments has been the establishment of long-lasting expert networks. In Finland, the first national RLE assessment brought together more than 100 specialists in eight thematic ecosystem groups, thereby creating new networks of habitattype specialists. These teams have remained active in supporting the second ecosystem red list and in advising authorities on ecosystem management and policy. Similarly, long-lasting networks have been established in South Africa following their consecutive ecosystem red lists in 2004, 2011, and 2018.

\section{Anticipated impacts on global biodiversity monitoring and international policy}

The systemic application of the IUCN RLE criteria at continental and national scales provides broad-scale information on the status of ecosystems that can be used in global biodiversity monitoring. Red List indices for ecosystems have been compiled for the Americas and Colombia, and these show clear signs of change in ecosystem status, extent, and condition (Ferrer et al. 2018). RLE indices have high potential to inform global biodiversity reporting, such as for the Aichi Targets of the Convention on Biological Diversity, the United Nations Sustainable Development Goals, the Global Environment Outlook, and the Intergovernmental Science-Policy Platform on Biodiversity and Ecosystem Services. 
The IUCN Red List Index for species is used to monitor progress toward nine of the 20 Aichi Targets (Driscoll et al. 2018). Our analysis indicates that IUCN RLE indices could inform monitoring toward 12 Targets (Table 2), in particular those related to the rate of loss natural habitats (Target 5) and the management of fisheries (Target 6), forestry (Target 7), ecosystem services (Target 14), and ecosystem resilience (Target 15).

Importantly, a focus on ecosystems allows the assessment of the intersection between communities, economies, and the ecosystems on which they depend. IUCN RLE data could be used to inform progress towards a number of United Nations Sustainable Development Goals, especially Goal 6 (sustainable water management), Goal 14 (life below water), and Goal 15 (life on land; Table S3). Data underpinning the IUCN RLE could also be used to inform the United Nations Framework Convention on Climate Change, in particular in relation to identifying priorities for implementing mitigation and adaptation actions.

Similarly, the IUCN RLE could contribute to the United Nations Convention to Combat Desertification and Land Degradation (UNCCD), specifically to the 2018-2030 Strategic Framework and the Land Degradation Neutrality commitment that aim to restore the productivity of vast expanses of degraded land (UNCCD 2017).

Increased coverage of RLE assessments in the future will improve our ability to monitor the state of biodiversity globally. Notably, IUCN RLE assessments undertaken at a national scale can already be used to inform international targets, including through national reporting mechanisms.

\section{Key areas for development}

\section{Toward a global RLE}

Completing a global IUCN RLE is a key focus to increase the impacts of the IUCN RLE at global and national scales. This will be achieved through a combination of global analyses 
and national and thematic assessments focusing on specific ecosystem types (e.g., boreal forests and coral reefs). To date, national assessments have played a key role in extending the coverage of the IUCN RLE, but adoption and uptake could be increased in Africa, Asia, and Oceania (Figure 1). Clear gaps exist in the application of the IUCN RLE to freshwater and marine realms (Table 1), with an extremely small portion of the global ocean having been assessed to date (Figure 1). Increased collaboration with marine and fisheries scientists to bridge disciplinary gaps will be key to expanding the IUCN RLE in marine ecosystems.

Also under development is a global ecosystem typology, which will support the completion of a global IUCN RLE and enable the integration of national and global assessments through a hierarchical structure. The upcoming IUCN RLE database will enable the integration of assessments conducted in different parts of the world and the compilation of key statistics to report against global biodiversity targets (Tables S2 and S3). Increased coverage of assessments will ensure better representativeness of threatened ecosystems into Key Biodiversity Areas (KBAs), which account for the representation of both threatened species and threatened ecosystems.

\section{Further integration with social and economic initiatives}

Mainstreaming the RLE into international and national policy will require increased coverage of assessments and pilot studies, as well as the development of inter-disciplinary collaborative networks to embed the IUCN RLE into a number of initiatives. Future pathways to increased social and economic impacts include linking RLE assessments with natural capital accounting (UN SEEA 2013), public health initiatives (e.g., to reduce the emergence of infectious diseases linked to ecosystem degradation; World Health Organization 2015), human well-being (Schleicher et al. 2018), disaster risk management (e.g., through NatureBased Solutions; Nesshöver et al. 2017), and sustainable livelihoods. The RLE could also be 
used further to inform business decisions, for example, to help assess and manage environmental and social risks in development projects (such as with the Tremarctos tool in Colombia and the Species and Threats database in Australia).

\section{Measuring conservation impact}

The impacts of IUCN RLE assessments should be monitored against the core goal of improving and sustaining the status of ecosystems globally. Current methods for assessing the impact of conservation actions include the use of set criteria (e.g., the Green List of Protected and Conserved Areas; Wells et al. 2016) and/or counterfactuals (e.g., the Green List of Species; Akçakaya et al. 2018). The impacts of red listing and conservation on ecosystems should be carefully monitored and information compiled to create a Green List of Ecosystems, as mandated by IUCN in 2012 (https://portals.iucn.org/library/node/44008).

\section{Conclusions}

Identifying impacts is key to justifying continued investment in biodiversity assessments and enabling analysis and strategic planning to maximize future impact (CSIRO 2018). In this policy perspective, we reported on the key outcomes and impacts of the IUCN RLE since its inception. We identified clear pathways to impact based on the experience of countries with pre-existing ecosystem red lists that are now adopting the IUCN RLE. We show that IUCN RLE assessments can be embedded at national scales into conservation legislation, land-use planning, monitoring and reporting, and ecosystem management. In addition, IUCN RLE indices are expected to provide key information to monitor progress toward international biodiversity targets. Expanding the coverage of IUCN RLE assessments, building capacity to undertake them, and establishing stronger policy instruments to manage red-listed ecosystems will be key to maximizing conservation impacts over the coming decades.

\section{Acknowledgements}


L. M. B. was supported by a Veski Inspiring Women fellowship to E. N. 


\section{References}

Akçakaya, H.R., Bennett, E.L., Brooks, T.M., Grace, M.K., Heath, A., Hedges, S., HiltonTaylor, C., Hoffmann, M., Keith, D.A., Long, B., Mallon, D.P., Meijaard, E., MilnerGulland, E.J., Rodrigues, A.S.L., Rodriguez, J.P., Stephenson, P.J., Stuart, S.N. \& Young, R.P. (2018). Quantifying species recovery and conservation success to develop an IUCN Green List of Species. Conserv. Biol.

Alaniz, A.J., Galleguillos, M. \& Perez-Quezada, J.F. (2016). Assessment of quality of input data used to classify ecosystems according to the IUCN Red List methodology: The case of the central Chile hotspot. Biol. Conserv., 204, 378-385.

Bland, L.M., Keith, D.A., Miller, R.M., Murray, N.J. \& Rodríguez, J.P. (eds. . (2017). Guidelines for the application of IUCN Red List of Ecosystems Categories and Criteria, Version 1.1. Gland, Switzerland: IUCN.

Burns, E.L., Lindenmayer, D.B., Stein, J., Blanchard, W., McBurney, L., Blair, D. \& Banks, S.C. (2015). Ecosystem assessment of mountain ash forest in the Central Highlands of Victoria, south-eastern Australia. Austral Ecol., 40, 386-399.

CSIRO. (2018). How CSIRO ensures it delivers impact [WWW Document]. URL https://www.csiro.au/en/About/Our-impact/Our-impact-model/Ensuring-we-deliverimpact

Driscoll, D.A., Bland, L.M., Bryan, B.A., Newsome, T.M., Nicholson, E., Ritchie, E.G. \& Doherty, T.S. (2018). A biodiversity-crisis hierarchy to evaluate and refine conservation indicators. Nat. Ecol. Evol., 2, 775-781.

Ferrer, J.R., Zager, I., Keith, D.A., Oliveira-Miranda, M.A. Rodgriguez, J.P., Josse, C., González-Gil, M. \& Miller, R. M., Zambrana-Torrelio, C. Barrow, E. (2018). An ecosystem risk assessment of temperate and tropical forests of the Americas with an outlook on future conservation strategies. Conserv. Lett. (accepted 23/11/2018).

Holdaway, R.J., Wiser, S.K. \& Williams, P.A. (2012). Status Assessment of New Zealand's Naturally Uncommon Ecosystems. Conserv. Biol., 26, 619-629.

IUCN. (2018). IUCN Red List of Ecosystems [WWW Document]. URL https://iucnrle.org/

Juffe-Bignoli, D., Brooks, T.M., Butchart, S.H.M., Jenkins, R.B., Boe, K., Hoffmann, M., Angulo, A., Bachman, S., Böhm, M., Brummitt, N., Carpenter, K.E., Comer, P.J., Cox, N., Cuttelod, A., Darwall, W.R.T., Di Marco, M., Fishpool, L.D.C., Goettsch, B., Heath, M., Hilton-Taylor, C., Hutton, J., Johnson, T., Joolia, A., Keith, D.A., Langhammer, P.F., Luedtke, J., Nic Lughadha, E., Lutz, M., May, I., Miller, R.M., Oliveira-Miranda, M.A., Parr, M., Pollock, C.M., Ralph, G., Rodríguez, J.P., Rondinini, C., Smart, J., Stuart, S., Symes, A., Tordoff, A.W., Woodley, S., Young, B. \& Kingston, N. (2016). Assessing the Cost of Global Biodiversity and Conservation Knowledge. PLoS One, 11, e0160640.

Keith, D.A., Rodríguez, J.P., Brooks, T.M., Burgman, M.A., Barrow, E.G., Bland, L., Comer, P.J., Franklin, J., Link, J., McCarthy, M.A., Miller, R.M., Murray, N.J., Nel, J., Nicholson, E., Oliveira-Miranda, M.A., Regan, T.J., Rodríguez-Clark, K.M., Rouget, M. \& Spalding, M.D. (2015). The IUCN Red List of Ecosystems: Motivations, Challenges, and Applications. Conserv. Lett., 8, 214-226.

Keith, D.A., Rodríguez, J.P., Rodríguez-Clark, K.M., Nicholson, E., Aapala, K., Alonso, A., 
Asmussen, M., Bachman, S., Basset, A., Barrow, E.G., Benson, J.S., Bishop, M.J., Bonifacio, R., Brooks, T.M., Burgman, M.A., Comer, P., Comín, F.A., Essl, F., FaberLangendoen, D., Fairweather, P.G., Holdaway, R.J., Jennings, M., Kingsford, R.T., Lester, R.E., Nally, R. Mac, McCarthy, M.A., Moat, J., Oliveira-Miranda, M.A., Pisanu, P., Poulin, B., Regan, T.J., Riecken, U., Spalding, M.D. \& Zambrano-Martínez, S. (2013). Scientific Foundations for an IUCN Red List of Ecosystems. PLoS One, 8, e62111.

Kontula, T. \& Raunio, A. (2009). New method and criteria for national assessments of threatened habitat types. Biodivers. Conserv., 18, 3861-3876.

Martinez-Harms, M.J., Caceres, H., Biggs, D. \& Possingham, H.P. (2017). After Chile's fires, reforest private land. Science, 356, 147-148.

Moreno, L.A., Rueda, C. \& Andrade, G.I. (2018). Biodiversidad 2017. Estado y tendencias de la biodiversidad continental de Colombia. Bogotá, D. C., Colombia.

Morgan, B. (2014). Research impact: Income for outcome. Nature, 511, S72-S75.

Nesshöver, C., Assmuth, T., Irvine, K.N., Rusch, G.M., Waylen, K.A., Delbaere, B., Haase, D., Jones-Walters, L., Keune, H., Kovacs, E., Krauze, K., Külvik, M., Rey, F., van Dijk, J., Vistad, O.I., Wilkinson, M.E. \& Wittmer, H. (2017). The science, policy and practice of nature-based solutions: An interdisciplinary perspective. Sci. Total Environ., 579, $1215-1227$.

Nicholson, E., Keith, D.A. \& Wilcove, D.S. (2009). Assessing the Threat Status of Ecological Communities. Conserv. Biol., 23, 259-274.

Norwegian Ministry of Climate and Environment. (2015). Meld. St. 14 (2015-2016) Report to the Storting (white paper): Nature for life, Norway's national biodiversity action plan.

PEFC Norway. (2015). Norwegian PEFC Forest Standard.

Pliscoff, P. (2015). Aplicación de los criterios de la Unión Internacional para la Conservación de la Naturaleza (IUCN) para la evaluación de riesgo de los ecosistemas terrestres de Chile. Santiago, Chile.

Republic of South Africa. (2009). Guideline regarding the determination of bioregions and the preparation of Bioregional Plans. Pretoria, South Africa.

Republic of South Africa. (2011). National list of ecosystems that are threatened or in need of protection. Pretoria, South Africa.

Reyers, B., Rouget, M., Jonas, Z., Cowling, R.M., Driver, A., Maze, K. \& Desmet, P. (2007). Developing products for conservation decision-making: lessons from a spatial biodiversity assessment for South Africa. Divers. Distrib., 13, 608-619.

Rodríguez, J.P., Rodríguez-Clark, K.M., Baillie, J.E.M., Ash, N., Benson, J., Boucher, T., Brown, C., Burgess, N.D., Collen, B., Jennings, M., Keith, D.A., Nicholson, E., Revenga, C., Reyers, B., Rouget, M., Smith, T., Spalding, M., Taber, A., Walpole, M., Zager, I. \& Zamin, T. (2011). Establishing IUCN Red List Criteria for Threatened Ecosystems. Conserv. Biol., 25, 21-29.

Schleicher, J., Schaafsma, M., Burgess, N.D., Sandbrook, C., Danks, F., Cowie, C. \& Vira, B. (2018). Poorer without It? The Neglected Role of the Natural Environment in Poverty 
and Wellbeing. Sustain. Dev., 26, 83-98.

Shepherd, E., Milner-Gulland, E.J., Knight, A.T., Ling, M.A., Darrah, S., van Soesbergen, A. \& Burgess, N.D. (2016). Status and Trends in Global Ecosystem Services and Natural Capital: Assessing Progress Toward Aichi Biodiversity Target 14. Conserv. Lett., 9, 429-437.

UN SEEA. (2013). System of Environmental-Economic Accounting 2012-Experimental Ecosystem Accounting.

UNCCD. (2017). Land Degradation Neutrality: transformative action, tapping opportunities.

Wells, S., Addison, P.F.E., Bueno, P.A., Costantini, M., Fontaine, A., Germain, L., Lefebvre, T., Morgan, L., Staub, F., Wang, B., White, A. \& Zorrilla, M.X. (2016). Using the IUCN Green List of Protected and Conserved Areas to promote conservation impact through marine protected areas. Aquat. Conserv. Mar. Freshw. Ecosyst., 26, 24-44.

World Health Organization. (2015). Connecting Global Priorities: Biodiversity and Human Health A State of Knowledge Review. 